\title{
Three-Dimensional Simulation of the McPherson Suspension System
}

\author{
Slavica MAČUŽIĆ, Jovanka LUKIĆ, Dragan RUŽIĆ
}

\begin{abstract}
Suspension system of a vehicle is one of the most important components of a vehicle that directly affects the safety, performance, noise level. Designing mechanisms of suspension system of the vehicle is a very complex task. At the beginning it is necessary to realize many requirements relating to the suspension system. McPherson suspension system is most commonly used on the front of the vehicle. Its application is most reflected in better movement of vehicles through the cornering as well as in a comfortable ride. Modern methods of construction of the system and its components involve the use of certain software packages. In this paper, using CATIA software package, numerical simulations were carried out for the most important parts of suspension. Finite element analysis was performed of the entire system to analyze effective stress and deformation changes in the function parameters in the analysis.
\end{abstract}

Keywords: finite element method; McPherson suspension system; vehicle; von Misses stress

\section{INTRODUCTION}

The modern concept of development of motor vehicles is reflected primarily in an increase of traffic safety in all modes of travel. For this reason, it is necessary to continuously improve the management system construction, braking and suspension, as well as the compliance of the functional characteristics of each model of vehicle. The automobile is a complex oscillatory system. Oscillations of automobile are mainly caused by the influence of unevenness in the road. They cause additional dynamic load of the vehicle and lead to fatigue and loads of drivers and passengers. Elements as a structural system connecting the front axle of a car with bodywork represent the front suspension. In the same way, the elements that connect the rear axle to the car body are the rear suspension. All elements together form the suspension of cars that include [1]:

- elastic elements (that provide flexible connections)

- conducting elements,

- damping elements.

In the study of oscillatory displacement of cars vertical oscillations and angular oscillations about the transverse axis of gravity have the greatest importance [2]. The study of oscillatory problem of the vehicle is aimed at the study and optimization of the following:

- ride comfort,

- driving stability,

- dynamic loads and strength of the structural elements of the vehicle.

Characteristics of the system, in the most general case, are estimated over the transfer function defined as the absolute value of the ratio of output functions according to input function (Fig. 1).

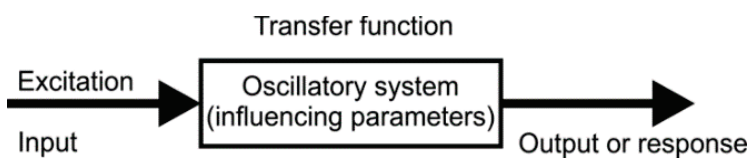

Figure 1 Schematic methods of the study of oscillatory problems [3]

\section{THE SUSPENSION SYSTEM FOR MOTOR VEHICLES}

The suspension system has the main task to pass all the reactive forces and moments that occur in the contact point of the tire and the ground on the car body with as much damping shock loads [4]. In addition, this system has a role to ensure the necessary stability of the vehicle especially when braking and moving in a cornering.

The suspension system presents a very complex system that consists of the following mechanisms:

- mechanism for guiding point (guiding elements)

- elastic supports (elastic elements)

- $\quad$ elements for damping of oscillations

- stabilizers.

Basic requirements that suspension system should fulfil are:

- optimal value of certain natural frequencies of oscillations depending on the static deflection

- $\quad$ sufficient dynamic pace that excludes the shocks stops

- required kinematic characteristics of the wheels to reduce tire wear, steering wheel stabilization and improvement of behavioural vehicles on the move

- optimal value of oscillation damping upgrades and wheels

- $\quad$ reliable transfer of forces and moments from the point to the body in all three directions

- $\quad$ reliability of the vehicle structure and the deployment of elements of suspension.

Suspension system of a motor vehicle achieves elastic connection between the basic structure of a motor vehicle with wheels and axles [5].

\section{LITERATURE REVIEW}

Colombo, D. et al. [6] have studied the causes of premature failure of the upper struct. Their work is fuelled by the fact that the car manufacturers use this component for 40 years without registering any faults, so it was necessary to study the structural behaviour of this component. A lot of experimental test and numerical analyses has been conducted to estimate the lifetime of this part. The results showed that impulsive load leads to damage of the upper struct, while static and dynamic loads, 
during usual working conditions, cannot be compared with the mentioned load.

Gadhia and Patel, [7] have shown that stability and comfort of the vehicle is entirely dependent on the suspension system. In this study, the researchers examined how the number of passengers in the vehicle affects performance of suspension system. Number of passengers that was used in the study was five and after a lot of comparisons and calculations, they came to the conclusion that this car cannot be used for five people, but only for a maximum of 4 persons.

Pathmasharma et al. [11] describe how rapid technological development in the area of automobile technology brings improvements in the comfort of the vehicle. Modifying the suspension system, that comfort can be maximized. They used ADAMS (Automatic Dynamics of Mechanical System) software to determine the forces acting on components of suspension system. In order to reduce the forces acting on the most sensitive system components, such as mounting points and track width, they did a certain geometrical modifications. After all the analysis, it was concluded that the conduct modifications produced good results in raising the performance of the vehicle.

Dodiya et al. [8] have shown that the suspension system has a big impact on driving comfort and stability on the road. Horizontal orientation of the shock absorbers helps designers to adapt other parts and have a greater stability due to a lower centre of gravity. After analysis, they concluded that a modification in design of the leading arm contributes to a more efficient suspension system.

Purushotham [9] has presented that today's cars use two systems of suspension: double wishbone suspension system and McPherson suspension. The reason for this is good dynamic performance and comfort of passengers. This author proposes a comprehensive development of a 2D mathematical model of McPherson suspension. That model would include, in addition to the vertical movement of the chassis, rotation and displacement for the wheel assembly. Using commercial software ANSYS he created realistic 2D model, and using Simulink he created the mathematical model in which he implemented dynamic equations to attain acceleration and the displacement of the chassis during the movement of vehicles through various road conditions. The conclusion is that the displacement and acceleration of the car chassis resulting in ANSYS are nearer to the values of the mathematical model. With these advanced models, it is possible to explore the impact of the suspension system on the comfort of the vehicle and its performance.

\section{FINITE ELEMENT FORMULATION}

Finite element has become the most popular method for the investigation of the suspension system of the vehicle $[10,11]$. This method solves a large number of differential equations to calculate von Misses stress and deformation of the model. The method has been widely used to predict mechanical behaviour of shock absorber in various driving situations such as driving over rough road, or sudden braking.

Principle of virtual work is one of the basic principles of continuum mechanics. Applying the boundary conditions in the equilibrium equations [12] virtual work of internal and external forces can be equal, and we have

$\delta W_{\text {int }}=\delta W_{\text {ext }}$

Matrix form of virtual work of the previous equation can be written as

$$
\begin{aligned}
& \delta W_{\text {int }}=\int_{V} \delta \boldsymbol{e}^{T} \boldsymbol{\sigma} \mathrm{d} V \\
& \delta W_{\mathrm{ext}}=\int_{V} \delta \boldsymbol{u}^{T} \boldsymbol{F}^{V} \mathrm{~d} V+\int_{S^{\sigma}} \delta \boldsymbol{u}^{T} \boldsymbol{F}^{S} \mathrm{~d} V+\sum_{i} \delta \boldsymbol{u}^{T} \boldsymbol{F}^{(i)}
\end{aligned}
$$

Applying the principle of virtual work and the constitutive relations for linear elastic material in matrix form, we have

$$
\sigma=C e
$$

Applying the concept of isoparametric interpolation [13] in the finite element, we can write the equation of equilibrium of finite elements

$$
\boldsymbol{K} \boldsymbol{U}=\boldsymbol{F}_{\text {ext }}
$$

where $\boldsymbol{K}$ is element stiffness matrix, $\boldsymbol{U}$ displacements at the nodes and $\boldsymbol{F}_{\text {ext }}$ - external forces in the element nodes. A basic assumption in the linear analysis of solids is that the moving solids are infinitesimally small, the material is linearly elastic, and that the nature of the boundary conditions remains unchanged under the action of external loads. About that, last equation is related to the linear analysis of solids because the moving of the nodes is linear function of external forces.

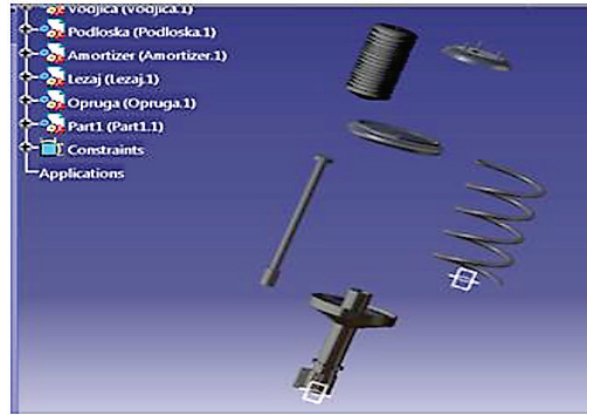

a) Individually presented elements of McPherson suspension system

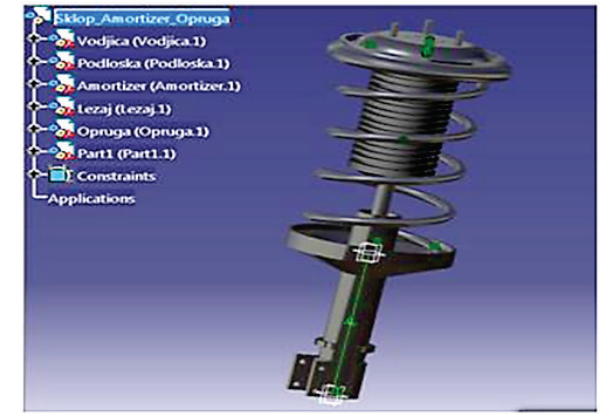

b) Coupled suspension system

Figure 2 Representation of McPherson suspension system 


\section{MODELLING OF SUSPENSION PARTS USING SOFTWARE PACKAGE Catia V5 R18}

By using Catia V5 R18 we modelled the existing vehicle parts which are used in series production, and which are used in almost all vehicles depending on the purpose and functionality of the system. These include a full set of shock absorbers and springs with a wheel of the vehicle in one unit, where were not taken into account the additional stabilizing elements in this analysis because the criteria are placed on the most critical parts of suspension. The influence of other elements in the analysis does not affect the simulation results, and therefore is not considered and is not taken into account. Fig. 2 shows such a suspension system. It is the McPherson suspension system.

The following table shows the material properties of all materials used in this analysis.

Table 1 Input data - characteristics of the material elements of suspension

\begin{tabular}{|c|c|c|c|c|}
\hline $\begin{array}{c}\text { Elements of } \\
\text { suspension } \\
\text { system }\end{array}$ & Material & $\begin{array}{c}\text { Young's } \\
\text { modulus } \\
(\mathrm{MPa})\end{array}$ & $\begin{array}{c}\text { Poisson's } \\
\text { ratio }\end{array}$ & $\begin{array}{c}\text { Density } \\
\left(\mathrm{kg} \cdot \mathrm{m}^{-3}\right)\end{array}$ \\
\hline Spring & Č4830 & 10500 & 0.33 & 7860 \\
\hline $\begin{array}{c}\text { Shock } \\
\text { absorber }\end{array}$ & $\check{C} 1830$ & 210000 & 0.30 & 7600 \\
\hline $\begin{array}{c}\text { Mug spring } \\
\text { shock } \\
\text { absorbers }\end{array}$ & $\check{C} 1720$ & 230000 & 0.30 & 7600 \\
\hline Upper Strut. & Č1830 & 210000 & 0.30 & 7600 \\
\hline The tyre & $\begin{array}{c}\text { dtyrene- } \\
\text { butadiene }\end{array}$ & 14 & 0.49 & 910 \\
\hline Rim & $\begin{array}{c}\text { aluminium } \\
\text { alloy }\end{array}$ & 70000 & 0.35 & 2710 \\
\hline
\end{tabular}

\section{RESULTS}

The following figures, from Fig. 3 to Fig. 8, show the results of numerical simulations - deformations and effective Von Misses stresses.

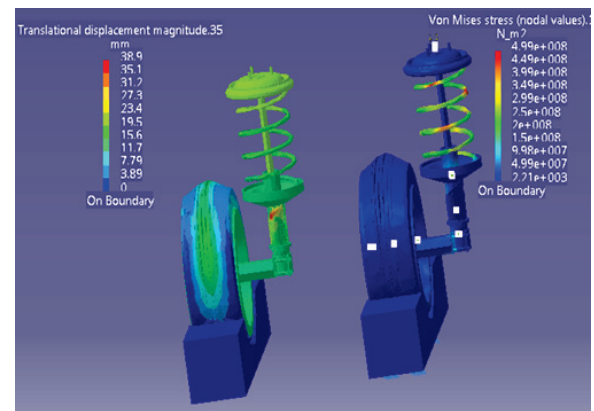

Figure 3 Total displacement and Von Misses stress at a pressure of $1.4 \mathrm{bar}$ and the force of $15000 \mathrm{~N}$

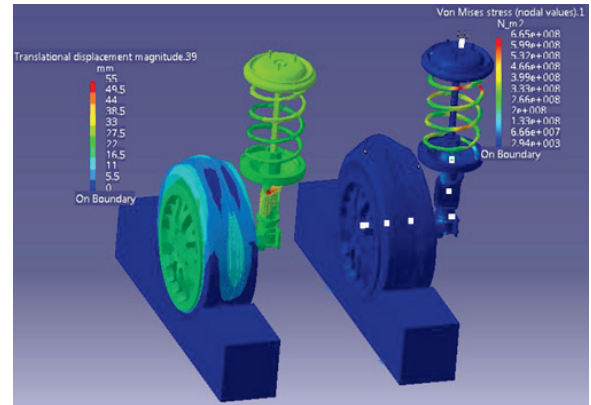

Figure 4 Total displacement and Von Misses stress at a pressure of $1.4 \mathrm{bar}$ and the force of $20000 \mathrm{~N}$

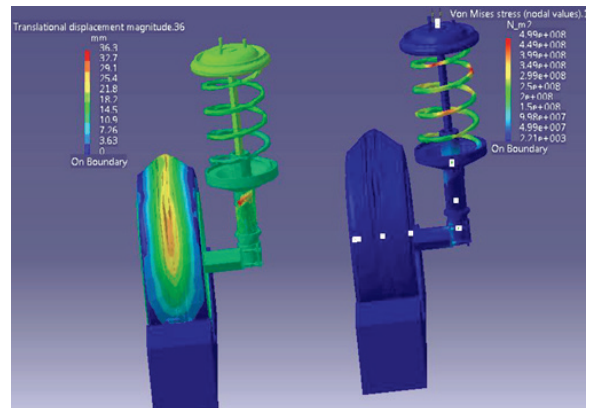

Figure 5 Total displacement and Von Misses stress at a pressure of 1.6 bar and the force of $15000 \mathrm{~N}$

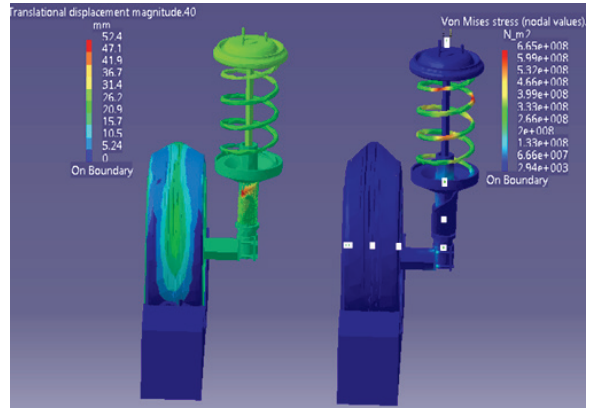

Figure 6 Total displacement and Von Misses stress at a pressure of 1.6 bar and the force of $20000 \mathrm{~N}$

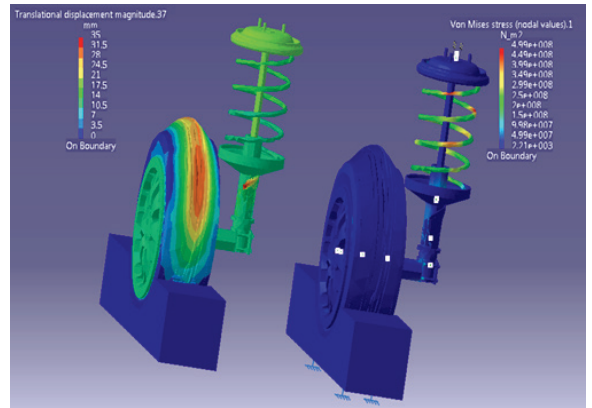

Figure 7 Total displacement and Von Misses stress at a pressure of $2.0 \mathrm{bar}$ and the force of $15000 \mathrm{~N}$

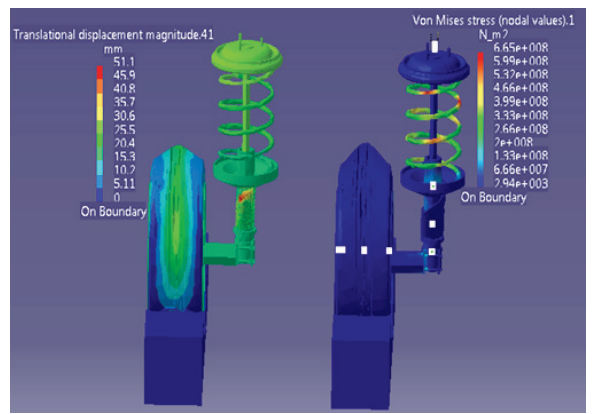

Figure 8 Total displacement and Von Misses stress at a pressure of 2.0 bar, and the force of $20000 \mathrm{~N}$

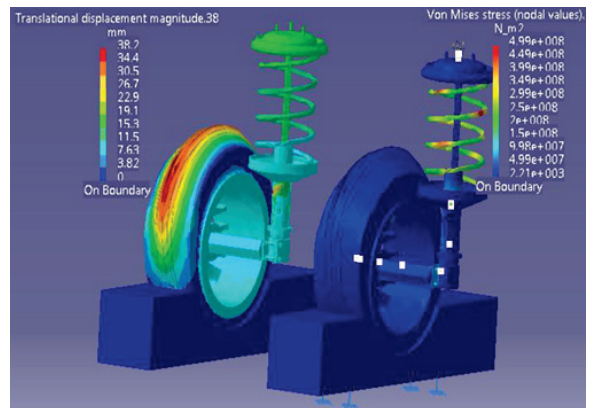

Figure 9 Total displacement and Von Misses stress at a pressure of 2.2 bar, and the force of $15000 \mathrm{~N}$ 


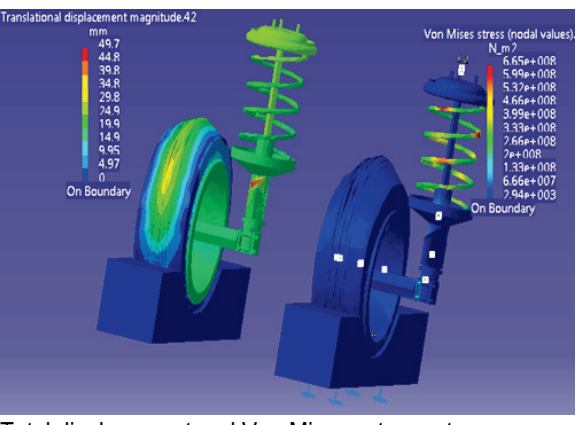

Figure10 Total displacement and Von Misses stress at a pressure of $2.2 \mathrm{bar}$ and the force of $20000 \mathrm{~N}$

The changes that followed during the simulation are primarily deformation of the spring which is changed nonlinearly with the change of pressure in the tire. Deformation changes can be clearly seen during the change of force that acts on the upper side spring on the guide piston shock absorbers. Another change that is very important is the impact variables, force and pressure in the tire on the dumping of the shock absorber. Damping is expressed through the characteristics of the rubber insert located in the housing shock absorbers instead of the fluid (oil). Moving the piston within the damper housing of shock absorber is a function of pressure and forces, which are represented in a short period of one second, wherein it adopts that the strain and stress occurring in a short time period equal the period of standstill. Therefore, static analysis interprets the changes in the parts of the structure and their displacements. Strains are expressed in terms of displacements in $\mathrm{mm}$, and the effective stress is expressed in MPa. Displacements vary from 20 to $50 \mathrm{~mm}$ non-linear distribution, depending on the characteristics of the applied materials and construction parts. The calculated value of the stress is below the allowable values for adopted materials for all parts of the suspension system. The greatest stresses occur in the spring because it is most exposed to load. Deformation of the most influential change in the tire, and he was introduced as the element that is most distorted in $\mathrm{mm}$.

\section{CONCLUSIONS}

Software package Catia V5 R18 describes all possible conditions of mentioned elements of suspension, as cinematic quantities, and the field strains and stresses. This work shows the greatest zone loads which are modelled, during the movement of vehicles on the road. The significance of these simulations is that before the installation of certain car parts can see their loads and behaviours. To make the system more realistic, we modelled all-important parts that affect the behaviour and stability of the vehicle in motion. The primary function of suspension is to meet the requirements of stability, security and mobility of vehicles. It performs several tasks, such as maintaining contact between the tire and the substrate, ensuring vehicle stability and protecting the body from shock loads that occur when moving over rough road. Performance suspension systems have progressed due to continuous achievement in cars in recent years. Today, as in the past, the development process for the suspension system has shown great interest among designers and manufacturers of vehicles. The geometry of the suspension system is an important factor in the design of the vehicle. Therefore, it is of great importance to use software packages that allow for the advance of the movement of certain parts or vehicle systems.

\section{Acknowledgement}

The Ministry of Education, Science and Technological Development of the Republic of Serbia, through Grant TR35041, supported this research.

\section{REFERENCES}

[1] Simić, D. (1975). The dynamics of motor vehicles fluctuations and suspension car. Faculty of Mechanical Engineering, Kragujevac.

[2] Stojić, B. (2012). The theory of the movement of road vehicles. Department of Motor Vehicles, Novi Sad.

[3] Den Hartog, J. P. (1972). Vibrations in mechanical engineering, construction books. Belgrade.

[4] Pathmasharma, S., Suresh, J. K., Viswanathan, P., \& Subramanian, R. (2013). Analysis of Passenger Car Suspension System Using Adams. International Journal of Science, Engineering and Technology Research (IJSETR), 2(5), 1186-1193.

[5] Filipović, I. (2006). Motorcycles and motor vehicles. Faculty of Mechanical Engineering, University of Tuzla.

[6] Colombo, D., Gobbi, M., Mastinu, G., \& Pennati, M. (2009). Analysis of an unusual McPherson suspension failure. Engineering Failure Analysis, 16, 1000-1010. https://doi.org/10.1016/j.engfailanal.2008.09.001

[7] Gadhia, U. D. \& Patel, S. P. (2012). Design and Problem Identification of Wagon-R car's rear suspension. International Journal of Emerging Technology and Advanced Engineering, 2(7), 111-113.

[8] Dodiya, D. V., Patel P. H., \& Chauhan, M. J. (2014). Dynamic Analysis of Leading Arm Suspensions System with Horizontal Spring Damper Assembly. International Journal of Advance Engineering and Research Development (IJAERD), 1(2), 1-6.

[9] Purushotham, A. (2013). Comparative Simulation studies on Mcpherson Suspension System. International Journal of Modern Engineering Research (IJMER), 3(3), 1377-1381.

[10] Gadhia, U. D. \& Sumant, P. P. (2012). Design and Problem Identification of Wagon-R car's rear suspension. International Journal of Emerging Technology and Advanced Engineering, 2(7), 111-113.

[11] Pathmasharma, S., Suresh, J. K., Viswanathan, P., \& Subramanian, R. (2013). Analysis of Passenger Car Suspension System Using Adams. International Journal of Science, Engineering and Technology Research (IJSETR), 2(5), 1186-1193.

[12] Kojic, M., Filipovic, N., Stojanovic, B., \& Kojic, N. (2008). Computer Modeling in Bioengineering - Theoretical Background, Examples and Software. John Wiley and Sons, 978-0-470-06035-3, Chichester, England. https://doi.org/10.1002/9780470751763

[13] Bathe, K. J. (1996). Finite Element Procedures. Prentice Hall, Inc., 097900490X, Englewood Cliffs, N. J. 


\section{Contact information:}

Slavica MAČUŽı́́, PhD student

University of Kragujevac, Faculty of Engineering,

Sestre Janjic 6, 34000 Kragujevac, Serbia

slavicamacuzic89@gmail.com

Jovanka LUKIĆ, Prof. PhD

University of Kragujevac, Faculty of Engineering,

Sestre Janjic 6, 34000 Kragujevac, Serbia

lukicj@kg.ac.rs

Dragan RUŽlć, Assist. Prof. PhD

University of Novi Sad, Faculty of Technical Sciences,

Department of Mechanization and Design Engineering,

Trg Dositeja Obradovića 6, 21000 Novi Sad, Serbia

ruzic@uns.ac.rs 